\title{
Non-Surgical Management of Periapical Cystic Lesion- A Case Report
}

\section{Gitanjali Swain* and Neelam Mittal}

Department of Conservative Dentistry and Endodontics, Faculty of Dental Sciences, Institute of Medical Sciences, Banaras Hindu University, Varanasi, Uttar Pradesh, India

\begin{abstract}
One of the most important objectives of root canal treatment is the elimination of microorganisms from the root canal system. Although chemo-mechanical preparation of root canals is able to reduce the number of bacteria, an intracanal medicament with antibacterial action is required to maximize the disinfection of the root canal system in infected cases. The need for intracanal medication increases in those cases where bacteria are resistant to routine treatment, and where the therapy cannot be successfully completed due to the presence of pain or continuing exudates. In this case we have used Metapex as intracanal medicament in a tooth with well-defined periapical pathology and patient was kept on follow up. A 6 month follow-up revealed healing of pathology which was followed by obturation of the root canal. This case study revealed calcium hydroxide and iodoform in paste form (Metapex) can be a favorable alternative for surgical endodontics.
\end{abstract}

Keywords: Chemo-mechanical preparation; Periapical pathology; Intracanal medicament; Non-surgical management

\section{Introduction}

It has been reported that bacteria lodged in the root canal system plays an important role in the development and maintenance of periapical lesions. Thus, the elimination of these bacteria is of great importance for apical and periapical healing after endodontic treatment $[1,2]$.

Although chemo-mechanical preparation of root canals is able to reduce the number of bacteria, an intracanal medicament with antibacterial action is required to maximize the disinfection of the root canal system in infected cases [3]. The need for intracanal medication increases in those cases where bacteria are resistant to routine treatment, and where the therapy cannot be successfully completed due to the presence of pain or continuing exudates [4].

Since its introduction in 1920, calcium hydroxide has been widely used in endodontics. It is a strong alkaline substance, with a $\mathrm{pH}$ of approximately 12.5 . In an aqueous solution, calcium hydroxide dissociates into calcium and hydroxyl ions. Various biological properties have been attributed to this substance, such as antimicrobial activity, high alkalinity, inhibition of tooth resorption and tissue dissolving ability [5-8]. Because of such effects, calcium hydroxide has been recommended for use as intracanal medicaments and in several other clinical situations. Several works have studied the mixture of other substances to calcium hydroxide with the purpose of improving some of its properties [9]. Among these additional substances are vehicles that can speed up or slow down ionic dissociation, substances that aid the filling of pulpal cavity by means of their consistency, substances used as antimicrobial medium and media that enhance radiopacity [10].

Metapex, is a silicone oil-based calcium hydroxide paste containing $38 \%$ iodoform which is used as an intra-canal medicament [11]. In this case we have used Metapex as the intra canal medicament.

\section{Case Report}

A 22 year male patient reported to the dental outpatient department with the chief complaint of pain in right lower back region. On clinical examination the tooth no. 45 was tender to percussion and no other lesion was there. On radiographic examination tooth no. 45 showed a well-defined periapical lesion extending to the mesial root of tooth no 46 on intra oral periapical radiograph. From vitality test for teeth 45 and 46, both teeth were found to be non-vital and both diagnosed as with chronic apical periodontitis associated with apical abscess.

Root canal treatment was planned for the tooth no. 45 initially. On access opening of the tooth profuse pus discharge was seen. After proper irrigation, a calcium hydroxide dressing was given and patient was recalled after 7 days. On the next visit when filling was removed again pus discharge was seen. Proper irrigation was done and calcium hydroxide dressing was given and patient was kept on follow up. On follow up visit on removal of filling again profuse drainage was seen. It was decided to do root canal treatment of tooth no. 46 as mesial root of the tooth was found to be affected.

Surgical treatment was avoided for the lesion with respect to tooth no. 45 as it is nearer to mental foramen. As tooth no. 45 had an open apex it was decided to use chlorohexidine as irrigant to avoid any soft tissue injury due to peri-apical extrusion of sodium hypochlorite. After irrigation with $2 \%$ chlorohexidine, calcium hydroxide iodoform mixture in paste form (Metapex) was given as root canal medicament. Patient was kept on a follow up of 45 days. After the time period an intraoral periapical radiograph of the affected region was taken which revealed remarkable healing of the periapical pathology.

As tooth no. 45 had an open apex it was decided to form apical stop by using MTA as already patient had a long treatment period. After setting of MTA canal was obturated and patient kept on follow up. On follow up after 6 months teeth 45 and 46 were clinically asymptomatic and intraoral periapical radiograph of patient showed healing of periapical pathology (Figure 1).

\section{Discussion}

Microorganisms creating periapical pathology produce toxic

*Corresponding author: Dr. Gitanjali Swain, Department of Conservative Dentistry and Endodontics, Faculty of Dental Sciences, Institute of Medical Sciences, Banaras Hindu University, Varanasi, Uttar Pradesh 221005, India, Tel: +91 7505919487; E-mail: gswain3@gmail.com

Received August 09, 2015; Accepted October 27, 2015; Published November 02,2015

Citation: Swain G, Mittal N (2015) Non-Surgical Management of Periapical Cystic Lesion- A Case Report. Dentistry 5: 342. doi:10.4172/2161-1122.1000342

Copyright: @ 2015 Swain G, et al. This is an open-access article distributed under the terms of the Creative Commons Attribution License, which permits unrestricted use, distribution, and reproduction in any medium, provided the original author and source are credited. 

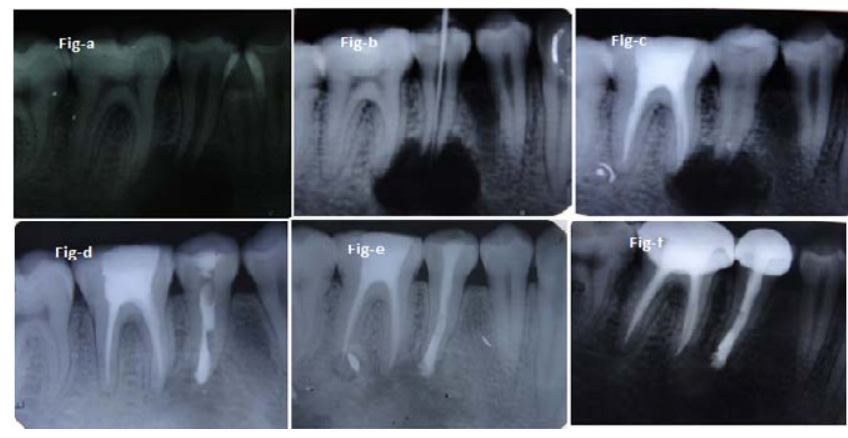

Fig-a: Pre-operative intra oral periapical radiograph; Fig-b: Working length determination; Fig-c: Obturation of 46 intra oral periapical radiograph; Fig-d: 45 days follow up intra oral peri apical radiograph; Fig-e: Intraoral peri apical radiograph of obturated tooth no. 45; Fig-f: 6 month follow up radiograph of patient showing healing of periapical pathology.

Figure 1: Periapical cystic lesion with 6 month follow-up.

products in periapical tissues, and contain endotoxins in their cell wall. Management of the teeth with pulp necrosis and chronic periapical reaction should not only be concerned with bacterial death, but also the inactivation of endotoxin.

Study by Abu Zeid et al. showed that calcium hydroxide detoxifies bacterial endotoxin [12]. Calcium hydroxide is clinically effective in eliminating microorganisms from root canal space. Lethal actions of calcium hydroxide on bacterial cells are probably caused by the damage to the bacterial cytoplasmic membrane, protein denaturation and damage to DNA. Calcium hydroxide, with its long acting antimicrobial and tissue solvent properties plays important role in endodontics. Calcium hydroxide for endodontic use comes as a paste form which can be easily introduced into the canal.

Metapex contains oily vehicles which are non-water soluble substance that promote the lowest solubility and diffusion of the paste within the tissues [13]. Metapex contains radiopaque component barium sulphate which can help to control the deposition of material when seen radiographically. Iodoform is incorporated to improve the antibacterial properties of the material. In the present case conventional root canal therapy combined with calcium hydroxide as an intracanal medicament lead to complete healing of the periapical pathology avoiding its surgical management.

\section{Conclusion}

Non-surgical management of periapical lesions have shown a high success rate. A non-surgical approach should always be adopted before resorting to surgery. The decompression and aspiration-irrigation techniques can be used when there is drainage of cystic fluid from the canals. These techniques act by decreasing the hydrostatic pressure within the periapical lesions. When there is no drainage of fluid from the canals, calcium hydroxide or the triple antibiotic paste can prove beneficial. Periodic follow-up examinations are essential and various assessment tools can be used to monitor the healing of periapical lesions. The surgical approach can be adopted for cases not responding to nonsurgical treatment, in obstructed or non-negotiable canals and for cases where long-term monitoring of periapical lesions is not possible.

\section{References}

1. Byström A, Sundqvist G (1981) Bacteriologic evaluation of the efficacy of mechanical root canal instrumentation in endodontic therapy. Scand J Dent Res 89: 321-328.

2. Tronstad L, Barnett F, Riso K, Slots J (1987) Extraradicular endodontic infections. Endod Dent Traumatol 3: 86-90.

3. Gomes BP, Souza SF, Ferraz CC, Teixeira FB, Zaia AA, et al. (2003) Effectiveness of $2 \%$ chlorhexidine gel and calcium hydroxide agains Enterococcus faecalis in bovine root dentine in vitro. Int Endod J 36: 267-275.

4. Athanassiadis B, Abbot PV, Walsh LJ (2007) The use of calcium hydroxide, antibiotics and biocides as antimicrobial medicaments in endodontics. Australian Dent J 52: S64-S82.

5. Soares JA, Leonardo MR, da Silva LA, Tanomaru Filho M, Ito IY (2006) Effect of rotary instrumentation and of the association of calcium hydroxide and chlorhexidine on the antisepsis of the root canal system in dogs. Brazil Oral Res 20: 120-126.

6. Mori GG, Ferreira FC, Batista FRS, Godoy MAS, Nunes DC (2009) Evaluation of the diffusion capacity of calcium hydroxide pastes through the dentinal tubules. Brazil Oral Res 23: 113-118.

7. Negri MR, Panzarini SR, Poi WR, Sonoda CK, Gulinelli JL, et al. (2008) Analysis of the healing process in delayed tooth replantation after root canal filling with calcium hydroxide, Sealapex and Endofill: a microscopic studt in rats. Dent Traumatol 24: 645-650.

8. de la Casa ML, Salas MM, Lópes ME, Raiden G (2008) Protein content in irrigation solutions in contact with pulp tissue. Acta Odontol Latinoam 21: 65-68.

9. Estrela C, Bammann LL, Pimenta FC, Pécora JD (2001) Control of microorganism in vitro by calcium hydroxide pastes. Int Endod J 34: 341-345.

10. Estrela C, Estrela CR, Hollanda AC, Decurcio Dde A, Pecora JD (2006) Influence of iodoform of antimicrobial potential of calcium hydroxide. J App Oral Sci 14: 33-37.

11. Stuart $\mathrm{CH}$, Schwartz SA, Beeson TJ, Owatz CB (2006) Enterococcus faecalis: its role in root canal treatment failure and current concepts in retreatment. J Endod 32: 93-98.

12. Abu Zeid ST (1992) Non surgical management of periapical pathosis associated with sinus tract in one appointment using calcium hydroxide based root canal sealer. Al Azhar Dent J 7: 321-333.

13. Heithersay GS (1975) Calcium hydroxide in treatment of pulpless teeth with associated pathology. J Br Endodon Soc 8: 74-93. 